\title{
Serotonin Modulates Photic Responses in the Hamster Suprachiasmatic Nuclei
}

\author{
M. A. Rea, ${ }^{1}$ J. D. Glass, ${ }^{2}$ and C. S. Colwell ${ }^{3}$ \\ ${ }^{1}$ Circadian Neurobiology Research Group, Armstrong Laboratory, Brooks AFB, Texas 78235, 'Department of Biological \\ Sciences, Kent State University, Kent, Ohio 44242, and ${ }^{3}$ Mental Retardation Research Center, UCLA Medical Center, Los \\ Angeles, California 90024
}

The aim of the present study was to examine the effects of serotonin agonists on three elements of the photic response in the hamster suprachiasmatic nuclei (SCN). Both serotonin and the selective 5-HT ${ }_{1 \mathrm{~A}}$ agonist 8-OH-DPAT inhibited field potentials recorded in the SCN in response to optic nerve stimulation in the hypothalamic slice preparation. The effects of both drugs were dose related over a concentration range of 1-50 $\mu \mathrm{M}$, and, in both cases, a maximal inhibition of approximately $60 \%$ was achieved at a concentration of 25-50 $\mu \mathrm{M}$. Systemic administration of 8-OH-DPAT inhibited light-stimulated Fos expression in the SCN. A regionally selective pattern of inhibition was observed, with decreases restricted predominately to the ventral and dorsal borders of the SCN. Finally, systemic administration of 8-OH-DPAT was found to dose-dependently attenuate light-induced phase shifts of the free-running activity rhythm. The effects of 8-OH-DPAT on light-induced phase advances were dose dependent. Injection of 8-OH-DPAT at a dose of $0.5 \mathrm{mg} / \mathrm{kg}$ caused $57 \%$ inhibition of light-induced phase advances, while a dose of $5 \mathrm{mg} / \mathrm{kg}$ inhibited the phase advance by $82 \%$. Injection of $0.05 \mathrm{mg} / \mathrm{kg} \mathrm{8-OH-DPAT}$ did not significantly inhibit light-induced phase advances. Injection of $5 \mathrm{mg} / \mathrm{kg} 8-\mathrm{OH}-$ DPAT alone did not significantly alter the phase of the activity rhythm. Similarly, injection of $5 \mathrm{mg} / \mathrm{kg} 8-O H-D P A T ~ 30$ min prior to light stimulation at CT14 completely inhibited light-induced phase delays, while this dose of the drug did not alter the phase of the activity rhythm when administered alone. These results support the hypothesis that serotonergic innervation of the SCN may serve to modulate the photic response of the SCN circadian oscillator.

[Key words: suprachiasmatic nuclei, 5-HT, 8-OH-DPAT, circadian rhythm, c-fos, field potentials, photic entrainment, Syrian hamster, retinohypothalamic tract]

The light-entrainable circadian pacemaker responsible for the generation of circadian rhythmicity in mammals is located in the suprachiasmatic nuclei (SCN) (for review, see Rusak and Zucker, 1979; Meijer and Reitveld, 1989). The isolated SCN

\footnotetext{
Received July 19, 1993; revised Nov. 9, 1993; accepled Nov. 24, 1993.

We gratefully acknowledge the skilled technical assistance of Ms. Anna Marie Michel and Mr. Matthew J. Cato. This work was supported by AFOSR Grants 92-AL-004 (M.A.R.) and 89-NL-071 (J.D.G.). C.S.C. is the recipient of an FESN Fellowship in circadian rhythms.

Correspondence should be addressed to Michael A. Rea, Ph.D., Circadian Neurobiology Research Group, Armstrong Laboratory (CFTO), 2504 D Drive, Suite 1, Brooks AFB, TX 78235-5104.

Copyright (C) 1994 Society for Neuroscience $0270-6474 / 94 / 143635-08 \$ 05.00 / 0$
}

continue to display circadian rhythmicity in vitro for several days (Green and Gillette, 1982; Earnest and Sladek, 1986; Newman and Hospod, 1986; Gillette and Reppert, 1987), indicating that rhythm generation is an intrinsic property of the SCN. Exposure of the intact animal to a light-dark (LD) cycle with a period near $24 \mathrm{hr}$ results in entrainment of the circadian oscillation (Rusak and Zucker, 1979) characterized by the development of stable phase relationships between pacemaker-driven rhythms and the imposed LD cycle. Potentially entraining photic information is conveyed to the $\mathrm{SCN}$ by at least two pathways: a monosynaptic projection from retinal ganglion cells (Moore and Lenn, 1971; Pickard, 1982; Johnson et al., 1988b), the retinohypothalamic tract (RHT), and an indirect retinal projection through the intergeniculate leaflet of the thalamus, the geniculohypothalamic tract (GHT) (Card and Moore, 1982). Although the GHT appears to modulate the response of the SCN to light, the RHT projection alone is both necessary and sufficient to support photic entrainment of the SCN pacemaker (Johnson et al., 1988a). In addition, the $\mathrm{SCN}$ receive a robust serotonergic projection from the midbrain raphe nuclei that terminates predominantly in the retinorecipient region of the nucleus (Azmitia and Segal, 1978; Moore et al., 1978).

In rodents, the raphe projection to the SCN represents one of the densest concentrations of serotonergic terminals in the brain (Azmitia and Segal, 1978). Disruption of the serotonergic projection to the SCN (Block and Zucker, 1976; Szafarczyk et al., 1981; Levine et al., 1986; Smale et al., 1990; Morin and Blanchard, 1991), and pharmacological manipulation of serotonin (5-HT) synthesis or degradation (Borbely et al., 1973; Honma et al., 1979; Duncan et al., 1988) have been shown to alter circadian behavioral and neuroendocrine rhythms in rodents. Furthermore, Prosser et al. (1990, 1992, 1993) and others (Medanic and Gillette, 1992; Shibata et al., 1992) have reported that application of serotonergic agonists during the subjective day results in stable phase advances of the circadian rhythm in single-unit activity in the hypothalamic slice preparation. This effect occurs in the presence of either $10 \mathrm{mM} \mathrm{Mg}^{2+}$ or $1 \mu \mathrm{M}$ tetrodotoxin (TTX), and appears to be mediated through 5-HT receptors (Prosser et al., 1992, 1993; Shibata et al., 1992). Similarly, Tominaga et al. (1992) and Edgar et al. (1993) have reported that $5-\mathrm{HT}_{1 \mathrm{~A}}$ receptor agonists cause phase advances of the free-running activity rhythm in rodents when administered during the subjective day. Together, these observations suggest that serotonin may play an important role in the regulation of the SCN circadian oscillator.

In addition to the apparent direct effect of serotonin on the circadian oscillator, there is evidence that serotonin may mod- 
ulate the response of the SCN oscillator to light. Liou et al. (1986) reported that exogenous serotonin inhibited optic nerve stimulation-induced field potentials in the SCN slice in vitro. Similarly, Miller and Fuller (1990) have shown that the activity of photically responsive SCN neurons is reduced by systemic administration of the nonspecific serotonin agonist quipazine. We have recently reported that quipazine significantly attenuates $c$-fos protein (Fos) expression in the $\mathrm{SCN}$ in response to a phase-advancing light treatment (Selim et al., 1993). Finally, 5,7-DHT lesioning of the serotonergic system, which depletes serotonin in the $\mathrm{SCN}$, alters the photic phase response curve (Morin and Blanchard, 1991), suggesting that endogenous serotonin may regulate the response of the SCN oscillator to light. While these observations point to a role for serotonin as a modulator of photic input to the SCN, this possibility has not been directly investigated. The aim of the present study, therefore, was to examine the effects of serotonin and selective agonists on three elements of the photic response in the SCN: (1) optic nerve stimulation-induced field potentials, (2) light-induced Fos expression in the SCN, and (3) light-induced phase shifts of the free-running activity rhythm.

\section{Materials and Methods}

Animals. Male, Syrian hamsters (Mesocricetus auratus; Charles River, Wilmington, MA) were housed in groups of six and maintained under a light:dark (LD) cycle of 14:10 (lights on at 02:00) for at least 2 weeks prior to experimentation. Cage level illuminance was approximately 200 lux and food and water were provided ad libitum.

Optic nerve stimulation-induced field potentials. Horizontal brain slices were prepared during the light phase. Hamsters were anesthetized with halothane until unresponsive and quickly decapitated. Brains were quickly removed (carefully cutting the optic nerves as far from the chiasm as possible), washed with ice-cold artificial cerebrospinal fluid (ACSF; $122 \mathrm{~mm} \mathrm{NaCl}, 3.8 \mathrm{~mm} \mathrm{KCl}, 1.2 \mathrm{mM} \mathrm{MgSO}_{4}, 1.2 \mathrm{mM} \mathrm{KH}_{2} \mathrm{PO}_{4}$, $25 \mathrm{~mm} \mathrm{NaHCO}_{3}, 2.5 \mathrm{~mm} \mathrm{CaCl}_{2}$, and $10 \mathrm{~mm}$ glucose), and cut into a block approximately $0.5 \times 0.5 \mathrm{~cm}$ centered around the optic chiasm. The tissue block was submerged in ice-cold ACSF and a single 400$500-\mu \mathrm{m}$-thick horizontal section containing the SCN, both optic nerves, and the optic chiasm was cut using a vibrating tissue slicer (Vibroslice, Campden Instruments, Sarasota, FL). The slice was allowed to incubate in a chamber containing ACSF saturated with $95 \% \mathrm{O}_{2}, 5 \% \mathrm{CO}_{2}$ for at least $2 \mathrm{hr}$ at room temperature $\left(22-23^{\circ} \mathrm{C}\right)$ prior to recording.

For electrophysiological measurements, the slice was transferred to a recording chamber and superfused with oxygenated ACSF. The waterjacketed recording chamber $(0.3 \mathrm{ml}$ volume) was composed of milled Plexiglas and the flow characteristics were designed to minimize pulsation. The floor of the chamber was covered with Sylgard (Dow Corning, Midland, MI) and the slice was secured in place with tungsten wire clips. A constant flow rate of $0.8 \mathrm{ml} / \mathrm{min}$ was maintained with the aid of a peristaltic pump. The preparation was maintained at $35^{\circ} \mathrm{C}$ during the recording session. Optic nerve stimulation was produced using a suction electrode made from polyethylene tubing containing a silver chloride-coated silver wire. Evoked potentials were recorded in the contralateral SCN using glass pipette microelectrodes filled with $3.0 \mathrm{~m}$ $\mathrm{NaCl}(0.8-1 \mathbf{M} \Omega$ resistance). Responses were amplified and displayed on a Gould model 1604 digital oscilloscope (Gould Electronics, Cleveland, $\mathrm{OH}$ ). Data were acquired, stored, and averaged on a Macintosh IIci computer equipped with an NB-DMA-8-G data acquisition board and running LABVIEW 2.5 (National Instruments, Austin, TX).

Activity rhythms. After at least 2 weeks in I.D 14:10, hamsters were transferred to individual cages equipped with running wheels and maintained in constant darkness (DD). Wheel-running activity was monitored continuously using a Zenith 248 computer running DATAQUEST III data acquisition software (supplied by Minimitter Co., Inc., Sunriver, OR). Graphical records of wheel-running behavior (actograms) were generated and analyzed using CIRCADIA software (Behavioral Cybernetics, Cambridge, MA) running on a Macintosh IIci computer.

The onset of wheel-running activity, designated as circadian time (CT) 12 , was used as a phase reference point for the timing of photic stimulation (Daan and Pittendrigh, 1976) as described previously (Rea, 1992).
Activity onset was defined as the first $6 \mathrm{~min}$ interval that was (1) coincident with a rate of wheel-turning activity that exceeded $10 \%$ of the maximum rate for the day, (2) preceded by a period of at least $4 \mathrm{hr}$ of inactivity, and (3) followed by a period of at lcast 30 min of sustained activity. The period of the free-running rhythm $(\tau)$ was calculated as the average amount of time between activity onsets over the $5 \mathrm{~d}$ prior to stimulation. The onset of activity on the day of stimulation was predicted by extrapolation of the least squares line through the activity onsets from the $5 \mathrm{~d}$ preceding the day of stimulation.

Light-induced phase shifts. After at least $10 \mathrm{~d}$ in DD, groups of hamsters received injections followed by light stimulation at either 2 circadian hours ( 1 circadian hour $=\tau / 24$ ) after the predicted activity onset (CT14), or 7 circadian hours after the predicted activity onset (CT19). Groups of hamsters received $0.3 \mathrm{ml}$ intraperitoneal injections of either vehicle ( $0.9 \%$ saline) or $8-\mathrm{OH}$-DPAT $30 \mathrm{~min}$ prior to light exposure. Injections were performed under dim red illumination $(<1$ lux $)$. Hamsters were transferred to the light stimulation chamber $(a 12 \mathrm{~cm} \times 20$ $\mathrm{cm}$ white metal cylinder) under dim red illumination and the chambcr was covered with a sheet of frosted glass. Each animal received $10 \mathrm{~min}$ of white light at an average illuminance of 20 lux at either CT14 or CT 19. The light stimulation apparatus was described previously (Rea, 1989). Light intensity was determined using a Tektronix J16 digital photometer with $\mathrm{J} 6511$ illuminance probe. After light stimulation, animals were returned to their respective wheel cages under DD. Animals that received drug injections without light treatment were handled as described above and returned to the cages under DD immediately after injection.

Quantitation of phase shifts. Animals remained in DD for 8-10 d after photic stimulation and wheel-running activity was monitored. Phase shifts were calculated as the difference between the projected times of activity onset (CT12) on the day after stimulation as determined by (1) back extrapolation of the least squares line through activity onscts on days 4-9 after stimulation, and (2) extrapolation of the least squares line calculated from activity onset data collected during the $5 \mathrm{~d}$ prior to and including the day of stimulation (Daan and Pittendrigh, 1976).

Light-induced Fos expression. Hamsters were maintained under DD in cages equipped with running wheels and the circadian activity rhythm was monitored as described above. After 8-10 d under DD, hamsters received intraperitoneal injections of either vehicle or 8-OH-DPAT 30 min prior to light exposure ( 20 lux of white light for $10 \mathrm{~min}$ as described above) at CT19. After light exposure, hamsters were returned to darkness. Hamsters were deeply anesthetized with pentobarbital $2 \mathrm{hr}$ after the onset of the light stimulation and perfused transcardially with 100 $\mathrm{ml}$ of heparinized phosphate-buffered saline ( $\mathrm{pH} 7.4$ ), followed by 100 $\mathrm{ml}$ of $4 \%$ paraformaldehyde in sodium phosphate buffer ( $\mathrm{pH}$ 7.4). Brains were removed and postfixed in $4 \%$ paraformaldehyde overnight at $4^{\circ} \mathrm{C}$, followed by $24 \mathrm{hr}$ at $4^{\circ} \mathrm{C}$ in $0.1 \mathrm{~m}$ sodium phosphate buffer (pH 7.4). Frontal sections $70 \mu \mathrm{m}$ thick were cut on a vibratome and incubated overnight at $4^{\circ} \mathrm{C}$ in Fos antiserum (c-fos $\mathrm{Ab}-2$ at 1:2000; Oncogene Science, Manhasset, NY). This antiserum was raised against a synthetic peptide (S G F N A D Y E A S S S R C) corresponding to residues 417 of human Fos. Fos-like immunoreactivity (Fos-LI) was detected using a Vectastain ABC kit (Vector Labs, Burlingame, CA) as described (Rea, 1989). All Fos-LI cell nuclei in both SCN throughout the rostrocaudal extent of the nucleus that were stained above background were counted in serial $70-\mu \mathrm{m}$-thick frontal sections.

Statistical analysis. Statistical significance was determined by ANO$\mathrm{VA}$ and differences between means were tested post hoc for significance $(p<0.05)$ using the Student-Neuman-Keuls test.

Drugs and reagents. Paraformaldehyde and all salts were obtained as ACS grade from Sigma Chemical Co. (St. Louis, MO). Serotonin, $( \pm$ )2-dipropylamino-8-hydroxy-1,2,3,4-tetrahydro-naphthalene hydrobromide (8-OH-DPAT), and 6-cyano-7-nitroquinoxaline-2,3-dione (CNQX) were obtained from Research Biochemicals (Natick, MA).

\section{Results}

Optic nerve stimulation-induced field potentials

Stimulation of the optic nerve elicited large field potentials in the contralateral SCN (Fig. 1). A typical field potential consisted primarily of a large-amplitude $(170 \pm 12 \mathrm{mV})$ negative wave (latency $=9-11 \mathrm{msec}$ ), preceded by one or two short-latency positive waves (Figs. 1, 2). The highest amplitude field potentials were observed when the recording electrode was located in the 

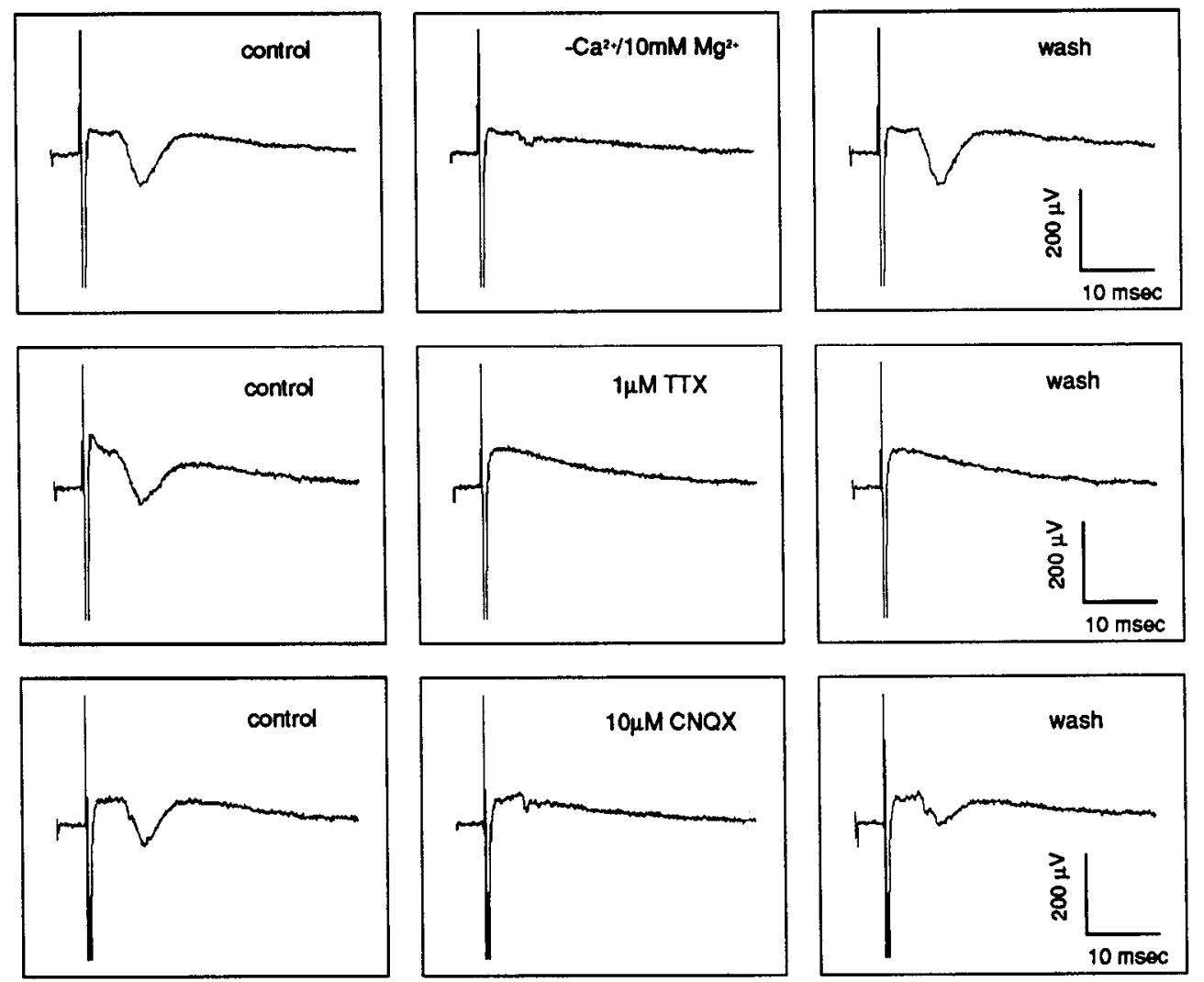

Figure 1. Optic nerve stimulationcvoked ficld potentials in the SCN. Responses were recorded in the contralateral $\mathrm{SCN}$ in response to stimulation $(0.7$ $\mathrm{mA}, 350 \mu \mathrm{sec}$ ) of the left optic nerve in the hypothalamic slice preparation. Each trace is the average of 16 trials. Drugs were applied for $10 \mathrm{~min}$ prior to data collection. Top traces, Effect of superfusion with ACSF containing $10 \mathrm{~mm}$ $\mathrm{Mg}^{2+}$ without added $\mathrm{Ca}^{2+}$. Middle traces, Effect of bath application of ACSF containing $1 \mu \mathrm{M}$ TTX. Bottom traces, Effect of bath application of $10 \mu \mathrm{M}$ CNQX. caudal one-third of the SCN. Therefore, all subsequent recordings were made in this region. The negative wave was reversibly attenuated after incubation in ACSF containing $10 \mathrm{mM} \mathrm{Mg}^{2+}$ without added $\mathrm{CaCl}_{2}$ (Fig. 1), but this treatment did not appear to affect the positive wave(s). Exposure of the slice to $1 \mu \mathrm{M}$ TTX completely blocked the response (Fig. 1). Furthermore, bath application of the competitive non-NMDA antagonist CNQX $(10 \mu \mathrm{M})$ significantly attenuated the response to optic nerve stimulation, indicating that the response is dependent upon excitatory amino acid neurotransmission. These observations suggest that the positive waves represent presynaptic events, while the negative wave is the result of transsynaptic activation of neuronal elements within the SCN (Shibata et al., 1984, 1986; Cahill and Menaker, 1989).

Bath application of serotonin $(0.1-25 \mu \mathrm{M})$ or $8-\mathrm{OH}-\mathrm{DPAT}$ $(0.1-50 \mu \mathrm{M})$ for $10 \mathrm{~min}$ reversibly attenuated the negative wave of the SCN field potential (Fig. 2). The effect of serotonin was completely reversed after only 10 min of washing in ACSF, while the effect of 8-OH-DPAT was more persistent, requiring up to $30 \mathrm{~min}$ of washing in ACSF to achieve recovery (Fig. 2). The effects of both drugs were dose related over a concentration range of $1-50 \mu \mathrm{M}$ (Fig. 3), and, in both cases, a maximal inhibition of approximately $60 \%$ was achieved at a concentration of 25-50 $\mu \mathrm{M}$. However, the response did not fully recover after exposure to high concentrations $(\geq 10 \mu \mathrm{M})$ of $8-\mathrm{OH}-\mathrm{DPAT}$. No apparent differences in the efficacy of serotonergic drugs applied to slices during the subjective day (8-14 hr after lights on) or subjective night (2-6 hr after lights off) were noted.

\section{Light-induced Fos expression}

Brief exposure of saline-injected hamsters to light at CT19 resulted in a characteristic pattern of Fos expression within the
SCN region (Fig. 4). Fos-LI cell nuclei were distributed throughout the SCN with a concentration in the caudal third of the nucleus. In addition, a large group of Fos-LI cells were observed extending outside the Nissl stain boundary of the SCN into the periventricular region. Injection of $8-\mathrm{OH}-\mathrm{DPAT}(5 \mathrm{mg} / \mathrm{kg}) 30$ min prior to light stimulation significantly reduced the number of Fos-LI cells, particularly along the ventral, dorsal, and medial borders of each nucleus (Fig. 4). A large percentage of cells located in the dorsolateral region were unaffected. At a dose of $5 \mathrm{mg} / \mathrm{kg}, 8-\mathrm{OH}-\mathrm{DPAT}$ reduced the number of Fos-LI cells in the SCN region by approximately $50 \%$ [saline + light $=1059$ \pm 171 cells $/ \mathrm{SCN} ; 8-\mathrm{OH}-\mathrm{DPAT}+$ light $=538 \pm 119 \mathrm{cells} / \mathrm{SCN}$ $(n=4) ; p<0.05]$. Injection of the drug alone did not induce Fos expression in the SCN (data not shown).

\section{Light-induced phase shifts}

Light stimulation 30 min after intraperitoneal injection of saline induced large, stable phase shifts of the free-running activity rhythm (Fig. 5). Stimulation at CT1 4 following a saline injection resulted in a phase delay of $-48 \pm 7 \min (n=6)$, while stimulation at CT 19 caused phase advances of $67 \pm 10 \mathrm{~min}(n=$ 9).

Injection of 8-OH-DPAT 30 min prior to light stimulation attenuated both the light-induced phase advances and delays (Fig. 5). The effect of 8-OH-DPAT on light-induced phase advances was dose dependent (Fig. 6). Injection of 8-OH-DPAT at a dose of $0.5 \mathrm{mg} / \mathrm{kg}$ caused $57 \%$ inhibition of light-induced phase advances $(29 \pm 11 \mathrm{~min} ; n=6 ; p<0.05$ vs saline + light), while a dose of $5 \mathrm{mg} / \mathrm{kg}$ inhibited the phase advance by $82 \%$. Injection of $0.05 \mathrm{mg} / \mathrm{kg}$ of $8-\mathrm{OH}-\mathrm{DPAT}$ did not significantly inhibit light-induced phase advances ( $72 \pm 12 \mathrm{~min}$ ). Injection of $5 \mathrm{mg} / \mathrm{kg} 8$-OH-DPAT alone did not significantly alter 

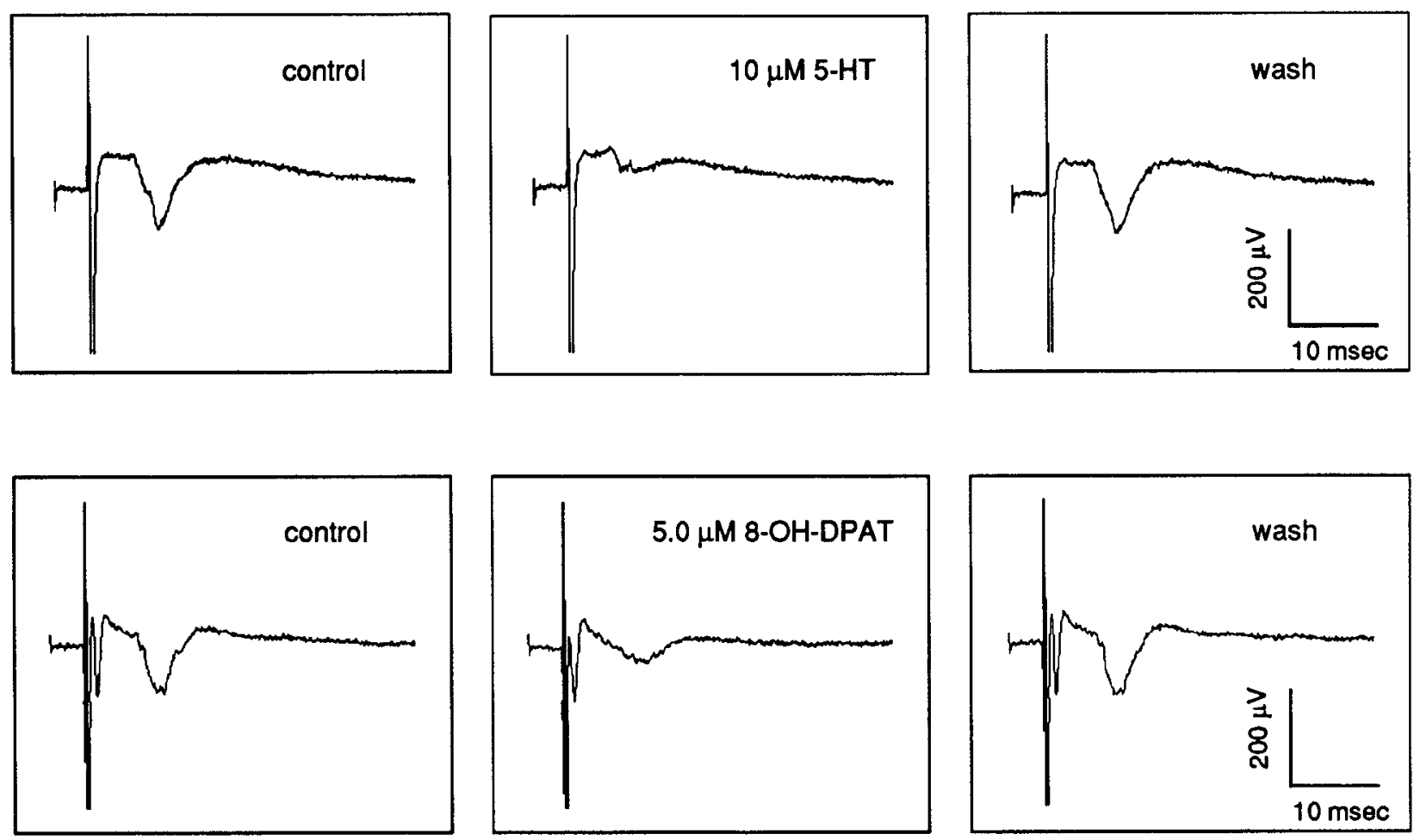

Figure 2. Effect of serotonin agonists on optic nerve stimulation-evoked field potentials in the SCN. Each trace is the average of 16 trials. Top traces, Effect of bath application of $10 \mu \mathrm{M}$ serotonin $(5-H T)$ for 10 min. Bottom traces, Effect of bath application of $5 \mu \mathrm{M} 8-\mathrm{OH}-\mathrm{DPAT}$ for $10 \mathrm{~min}$.

the phase of the activity rhythm (4 $\pm 9 \mathrm{~min}$; Fig. 6). Similarly, injection of $5 \mathrm{mg} / \mathrm{kg} 8$-OH-DPAT $30 \mathrm{~min}$ prior to light stimulation at CT 14 completely inhibited light-induced phase delays $(-7 \pm 9 \mathrm{~min} ; n=7 ; p<0.05$ relative to saline + light group; Figs. 5,6), while this dose of the drug did not alter the phase of the activity rhythm when administered alone $(0.3 \pm 8 \mathrm{~min})$.

\section{Discussion}

The present study explored the role of serotonin as a possible modulator of light input to the SCN circadian system. Our results demonstrate that both serotonin and the selective $5-\mathrm{HT}_{1 \mathrm{~A}}$ agonist 8-OH-DPAT (Middlemiss and Fozard, 1983) inhibit field potentials recorded in the SCN in response to optic nerve stimulation in the hypothalamic slice preparation. In addition, systemic administration of 8-OH-DPAT also inhibited lightstimulated Fos expression in the SCN. This effect was regionally selective. Finally, systemic administration of 8-OH-DPAT was found to dose-dependently attenuate light-induced phase shifts of the free-running activity rhythm. These results support the hypothesis that the serotonergic projection to the SCN may serve to modulate the response of SCN neurons that mediate photic regulation of the SCN circadian oscillator.

Electrical stimulation of the optic nerve elicited field potentials in the contralateral SCN similar to those reported for rat (Liou et al., 1986) and mouse (Cahill and Menaker, 1989) preparations. Field potentials were blocked by pretreatment with 1 $\mu \mathrm{M}$ TTX and the appearance of negative potential was dependent upon the presence of calcium in the buffer, and was inhibited by the competitive non-NMDA antagonist CNQX. These observations indicate that this signal represents a transsynaptic response to electrically evoked action potentials propagating along the optic nerve. Since the indirect retinal projection (Card and Moore, 1982) to the SCN was severed during slice prepa- ration, it is likely that these evoked SCN potentials are due to activation of the RHT.

Bath application of both serotonin and 8-OH-DPAT dosedependently inhibited optic nerve-evoked field potentials. The efficacy of serotonin as an inhibitor of SCN field potentials observed in the present study are similar to those reported by Liou et al. (1986) in the rat SCN. In both studies, serotonin achieved a maximal inhibition of approximately $60-70 \%$. In the present study, the degree of inhibition appeared to be dependent upon electrode location, although this was not systematically investigated. These results confirm and extend those of Liou et al. (1986) and suggest that exogenous serotonin is capable of limiting the response of SCN neurons to RHT stimulation, possibly by acting through a $5-\mathrm{HT}_{1 \mathrm{~A}}$ receptor.

The photic regulation of the expression of immediate-early genes, including $c$-fos, in the rodent $\mathrm{SCN}$ has been extensively demonstrated (Rea, 1989, 1992, 1993a; Kornhauser et al., 1990, 1992; Rusak et al., 1990, 1992; Colwell and Foster, 1992). Although the functional significance of this regulation is currently unclear (Rea et al., 1993b), Fos induction does appear to provide a useful marker signaling the photic activation of cells within the SCN. Our results demonstrate that the 5-HT receptor agonist 8-OH-DPAT partially inhibits photic induction of Fos-LI in the hamster SCN. Furthermore, a regionally selective pattern of inhibition was observed, with decreases restricted predominately to the ventral and dorsal borders of the SCN. Fos-LI cells in the dorsomedial region of the $\mathrm{SCN}$, as well as those Fos-LI cells located dorsal to the SCN in the subperiventricular region, were largely spared. The pattern of inhibition by $8-\mathrm{OH}-\mathrm{DPAT}$ of light-induced Fos expression observed in the present study corresponds roughly to the pattern of serotonergic innervation reported previously (Morin and Blanchard, 1991; Morin et al., 1992). Similar regionally selective effects of various pharma- 

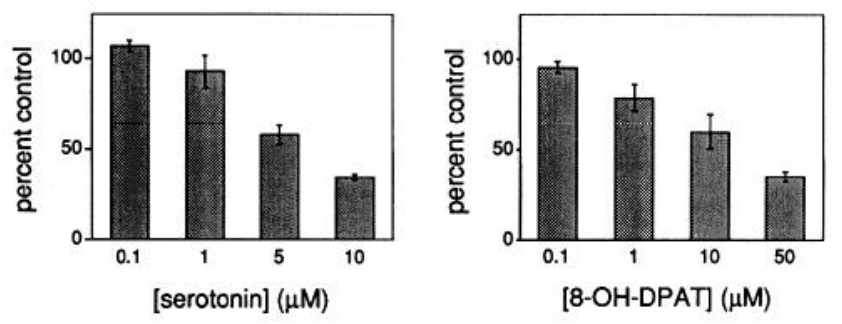

Figure 3. Dose-response data for inhibition of optic nerve stimulation-evoked field potentials in the SCN slice preparation. Drugs were bath applied for $10 \mathrm{~min}$ prior to data collection and slices were washed until full recovery of the response was achieved prior to exposure to successive drug doses. Data represent the mean \pm SEM of four or five determinations.

cological agents on the pattern of photic induction of Fos-LI in the SCN have been previously observed (Abe et al., 1991, 1992; Kaufman et al., 1992; Rea et al., 1993; Selim, 1993). These findings may reveal regional differences in the neurochemical regulation of light-induced Fos-LI in the SCN and suggest that 8-OH-DPAT prevents photic activation of some SCN neurons.

Systemic injection of 8-OH-DPAT dose-dependently inhibited light-induced phase advances and delays (one dose tested) of the free-running activity rhythm. A similar but less pronounced effect was observed with systemic injection of the nonspecific serotonin agonist quipazine (data not shown). In agreement with the work of others (Tominaga et al., 1992; Edgar et al., 1993), injection of DPAT alone at either CT14 or CT19 did not alter the phase of the activity rhythm. While the neuroanatomical site of action of systemically administered 8-OH-DPAT is unknown, these results suggest that this 5-HT receptor agonist prevents photic information from reaching the circadian oscillator. In view of the observations that 8-OH-DPAT also inhibits evoked field potentials and Fos expression, one simple explanation of these results is that 8-OH-DPAT hyperpolarizes retinoreceptive neurons in the $\mathrm{SCN}$, attenuating light-induced depolarization, and thus blocking the response of the circadian oscillator.

In the present study, we did not attempt to characterize the receptor species responsible for the effects of serotonin and $8-\mathrm{OH}-$ DPAT on photic responses in the SCN. However, in view of the fact that 8 -OH-DPAT appears to be a selective $5-\mathrm{HT}_{1 \mathrm{~A}}$ agonist (Middlemiss and Fozard, 1983), one must consider the possibility that a $5-\mathrm{HT}_{1 \mathrm{~A}}$-like receptor may be involved. Recently, Tominaga et al. (1992) and Edgar et al. (1993) have reported that $5-\mathrm{HT}_{1 \mathrm{~A}}$ agonists cause phase advances of the freerunning activity rhythm in rodents when administered during the subjective day. Similarly, Prosser et al. (1993) have reported that the effects of serotonergic agonists, including 8-OH-DPAT, applied during the subjective day on the phase of the single unit rhythm in the SCN slice could be blocked by the selective 5- $\mathrm{HT}_{1 \mathrm{~A}}$ antagonist NAN190 (Glennon et al., 1988). However, in a recent study of serotonin receptor gene expression in the rat SCN, Roca et al. (1993) reported only a very low level of $5-\mathrm{HT}_{\mathrm{IA}}$ receptor expression in the SCN. Recently, a novel serotonin receptor subtype, denoted $5-\mathrm{HT}_{7}$, was detected in the $\mathrm{SCN}$ (Lovenberg et al., 1993). This receptor has high affinity for $5-\mathrm{HT}_{1 \mathrm{~A}}$ agonists and also binds certain 5- $\mathrm{HT}_{2}$ antagonists, including ritanserin. Preliminary data suggest that the pharmacology of serotonergic effects on the single-unit rhythm in the SCN slice is consistent with the involvement of a 5-HT, receptor (Lovenberg et al.,
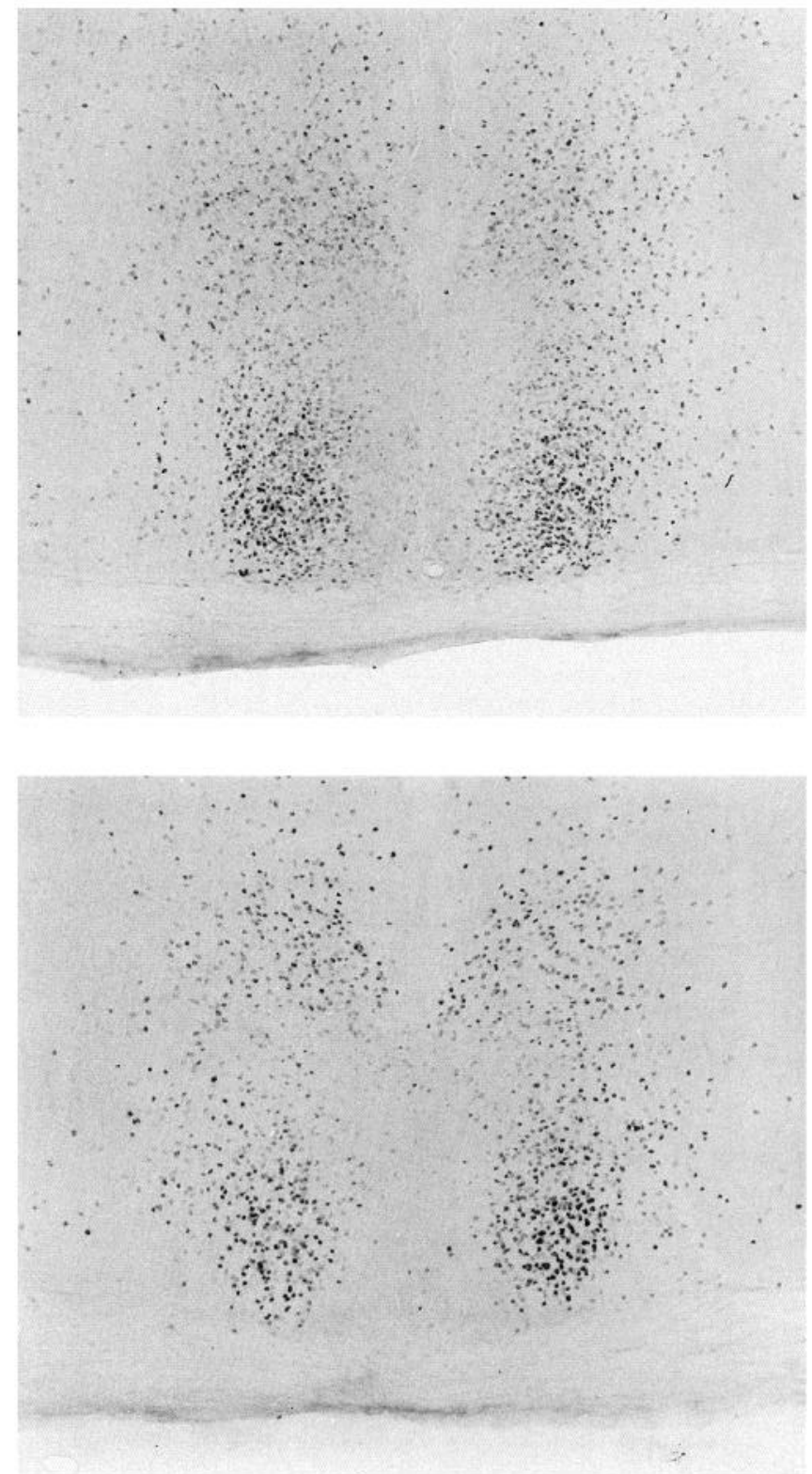

Figure 4. Representative photomicrographs demonstrating the effect of systemic administration of 8-OH-DPAT on light-induced Fos expression in the SCN. Free-running hamsters maintained in constant darkness received intraperitoneal injections of either saline (top) or 5 $\mathrm{mg} / \mathrm{kg} 8$-OH-DPAT in saline (bottom) $30 \mathrm{~min}$ prior to light exposure (40 lux for $10 \mathrm{~min}$ ) at CT19. Animals were perfused $90 \mathrm{~min}$ after the onset of light exposure. Magnification, $75 \times$.

1993). However, an elucidation of the nature of the receptor that mediates the effects of serotonin agonists on the photic response of the SCN circadian oscillator awaits further investigation.

The present study provides three lines of evidence strongly suggesting that serotonin may modulate the response of the SCN circadian oscillator to light. Although the evidence provided in the present study is purely pharmacological in nature, previously published work supports the suggestion that endogenous serotonergic activity may play a role in the photic entrainment of the SCN oscillator. Chemical lesioning of the brain serotonergic system with 5,7-DHT, which depletes serotonin in the SCN, alters the phase angle of entrainment of the activity rhythm in 
Figure 5. Representative actograms demonstrating the effect of systemic administration of 8-OH-DPAT on lightinduced phase shifts of the free-running activity rhythm. Hamsters were maintained under constant darkness and wheel-running behavior was monitored by computer. Top, Hamsters received intraperitoneal injections of normal saline at either CT 13.5 or CT18.5, followed by brier light exposure (40 lux, $10 \mathrm{~min}$ ) at CT14 (left) or CT19 (right), respectively. Middle, Hamsters received intraperitoneal injections of 5 $\mathrm{mg} / \mathrm{kg}$ of 8-OH-DPAT at either CT 13.5 or CT 18.5 , followed by brief light exposure (40 lux, $10 \mathrm{~min}$ ) at CT14 (left) or CT 19 (right), respectively. Bottom, Hamsters received intraperitoneal injections of $5 \mathrm{mg} / \mathrm{kg}$ of $8-\mathrm{OH}-D P A T$ at either CT13.5 or CT18.5. Approximate times of light onset are indicated by the inverted triangles.
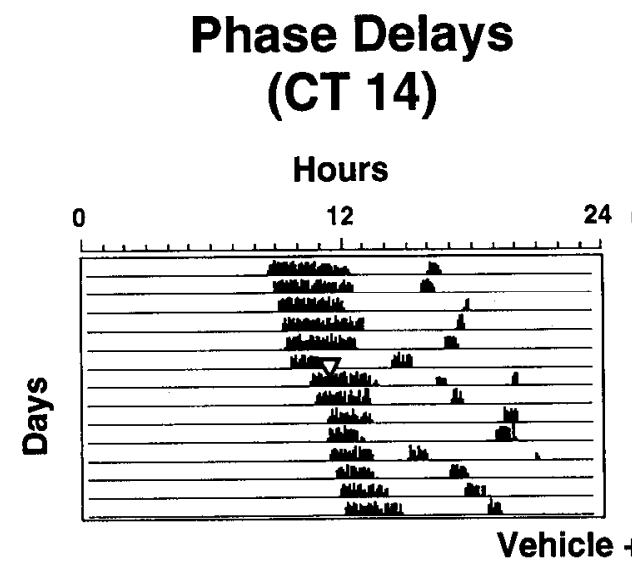

\section{Phase Advances (CT 19)}

Hours

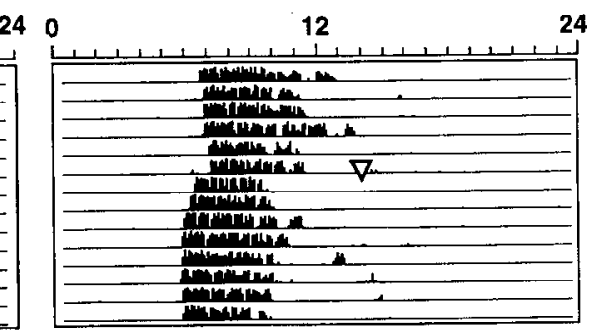

Vehicle + Light
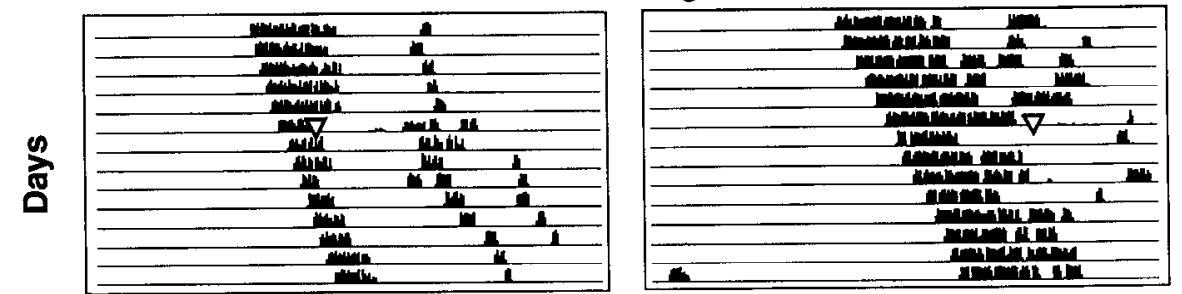

8-OH-DPAT + Light
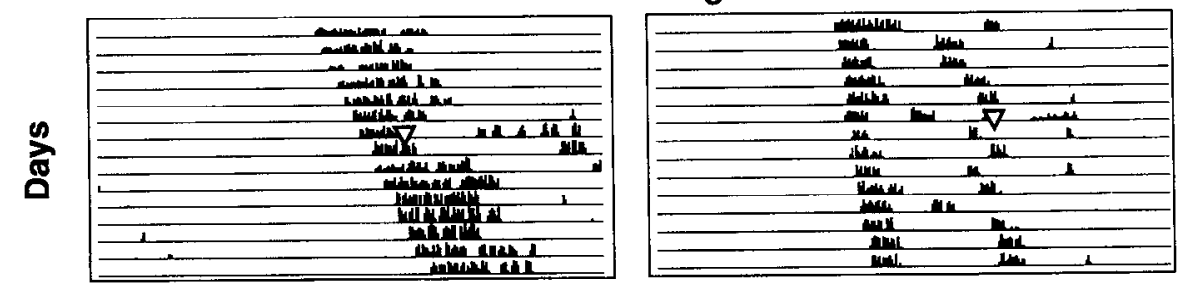

8-OH-DPAT alone

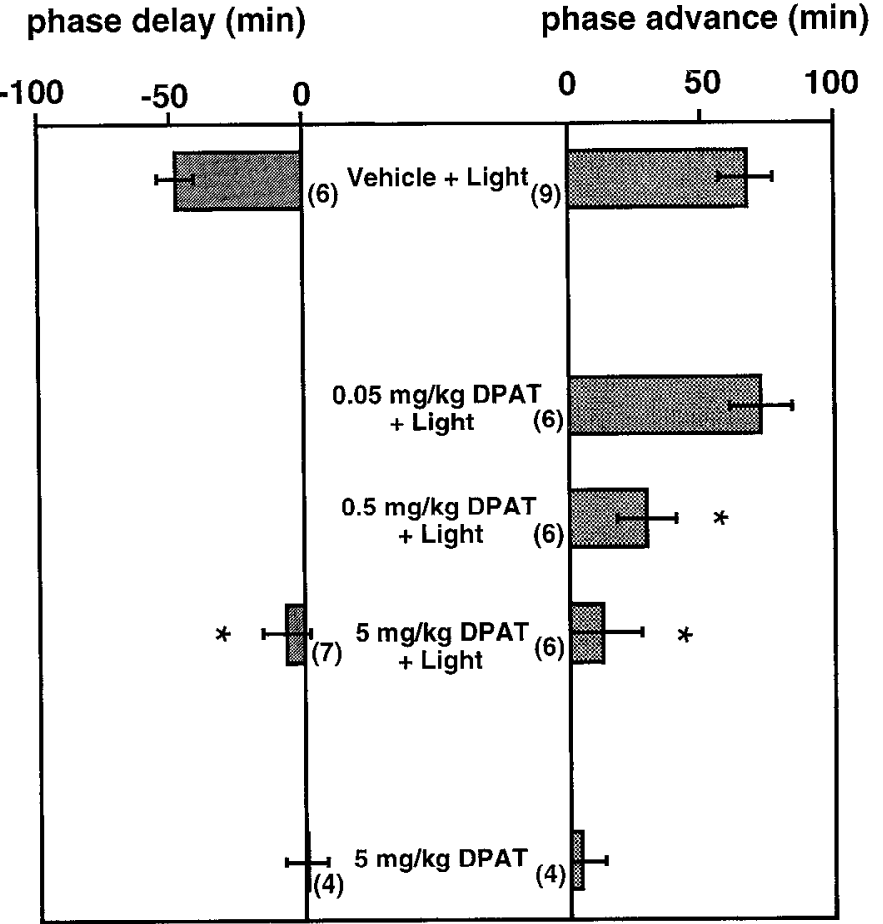

Figure 6. Effect of systemic administration of 8-OH-DPAT on lightinduced phase advances (right) and delays (left) of the free-running activity rhythm. Data represent the mean \pm SEM of the number of determinations indicated in parentheses. Asterisks indicate statistically significant differences $(p<0.05)$ relative to the vehicle + light group. hamsters (Smale et al., 1990) and augments the phase delay portion of the photic phase-response curve (Morin and Blanchard, 1991). In this regard, it is important to note that the daily patterns in serotonin turnover in the SCN (Faradji et al., 1983) and in the extracellular concentration of 5-HIAA in the SCN (Glass et al., 1992) show strong diurnal rhythmicity with the highest rate of turnover occurring during the early subjective night (Hery et al., 1982; Faradji et al, 1983; Ramirez et al., 1987; Glass et al., 1992). Furthermore, the rhythm in 5-HIAA release in the SCN (Glass et al., 1993), as well as that of serotonin content in the hypothalamus (Ferraro and Seger, 1990), is absent in animals maintained in constant darkness, indicating that diurnal changes in serotonergic activity in the SCN are driven, to some extent, by the LD cycle. Thus, the serotonergic innervation of the SCN may convey photic information to the circadian system. However, the functional significance of serotonin's modulation of the photic input to the SCN remains unclear.

In summary, exogenous serotonin and the selective $5-\mathrm{HT}_{1 \mathrm{~A}}$ agonist 8-OH-DPAT inhibit field potentials recorded in the SCN in response to optic nerve stimulation in the hypothalamic slice preparation. In addition, systemic administration of 8-OHDPAT inhibits light-stimulated Fos expression in the SCN in a regionally selective manner. Finally, systemic administration of 8-OH-DPAT dose-dependently attenuates light-induced phase shifts of the free-running activity rhythm. These results, together with those of previous reports concerning the effects of disruption of the serotonergic system with 5,7-DHT (Morin and Blanchard, 1991; Smale et al., 1992) and the effects of serotonin agonists on response of SCN neurons to photic and optic nerve 
stimulation (Liou et al., 1986; Miller and Fuller, 1990), support the hypothesis that serotonin serves to regulate the photic response of the SCN circadian oscillator and, therefore, may play a role in the photic entrainment process. However, confirmation of the role of serotonin in the regulation of photic responsiveness in the SCN will require the demonstration that local manipulation of the serotonergic afferents to the $\mathrm{SCN}$, including local administration of agents that enhance or modulate serotonin synthesis and release, as well as specific serotonin antagonists, into the $\mathrm{SCN}$ region will produce predictable alterations in the photic response of the SCN oscillator.

\section{References}

Abe H, Rusak B, Robertson HA (1991) Photic induction of Fos protein in the suprachiasmatic nucleus is inhibited by the NMDA receptor antagonist MK-801. Neurosci Lett 127:9-12.

Abe H, Rusak B, Robertson HA (1992) NMDA and non-NMDA receptor antagonists inhibit photic induction of Fos protein in the hamster suprachiasmatic nucleus. Brain Res Bull 28:831-835.

Azmitia EC, Segal M (1978) An autoradiographic analysis of the differential ascending projections of the dorsal median raphe nuclei in the rat. J Comp Neurol 179:641-668.

Block M, Zucker I (1976) Circadian rhythms of rat locomotor activity after lesions of the midbrain raphe nuclei. J Comp Physiol 109:235247.

Borbely AA, Huston JP, Waser PG (1973) Physiological and behavioral effects of parachlorophenylalanine in the rat. Psychopharmacology 31:131-142.

Cahill GM, Menaker M (1989) Effects of excitatory amino acid receptor antagonists and agonists on suprachiasmatic nucleus responses to retinohypothalamic tract volleys. Brain Res 479:76-82.

Card JP, Moore RY (1982) Ventral lateral geniculate nucleus efferents to the rat supra-chiasmatic nucleus exhibit avian pancreatic polypeptide-like immunoreactivity. J Comp Physiol 206:390-396.

Colwell CS, Foster RG (1992) Photic regulation of Fos-like immunoreactivity in the suprachiasmatic nucleus of the mouse. J Comp Neurol 324:135-142.

Daan S, Pittendrigh CS (1976) A functional analysis of circadian pacemakers in nocturnal rodents: II. The variability of phase response curves. J Comp Physiol 106:253-266.

Duncan WC, Tamarkin L, Sokolove PG, Wehr TA (1988) Chronic chlorgyline treatment of Syrian hamsters: an analysis of effects on the circadian pacemaker. J Biol Rhythms 3:305-322.

Earnest DJ, Sladek CD (1986) Circadian rhythms of vasopressin release from individual rat suprachiasmatic explants in vitro. Brain Res 382:129-133.

Edgar DM, Miller JD, Prosser RA, Dean RR, Dement WC (1993) Serotonin and the mammalian circadian system: II. Phase-shifting rat behavioral rhythms with serotonergic agonists. J Biol Rhythms 8:17-13.

Faradji H, Cespuglio R, Jouvet M (1983) Voltammetric measurements of 5-hydroxyindole compounds in the suprachiasmatic nuclei: circadian fluctuations. Brain Res 279:111-119.

Gillette MU, Reppert SM (1987) The hypothalamic suprachiasmatic nuclei: circadian patterns of vasopressin secretion and neuronal activity in vitro. Brain Res Bull 19:135-139.

Glass JD, Randolph WW, Ferreira SA, Rea MA, Hauser UE, Blank JL, de Vries MJ (1992) Diurnal variation in 5-hydroxyindoleacetic acid output in the suprachiasmatic region of the Siberian hamster assessed by in vivo microdialysis: evidence for nocturnal activation of serotonin release. Neuroendocrinology 56:582-590.

Glass JD, Hauser UE, Blank JL, Selim M, Rea MA (1993) Differential timing of amino acid and 5-HIAA release in the suprachiasmatic hypothalamus. Am J Physiol 265:R504-R511.

Glennon RA, Naiman NA, Lyon RA, Titeler M (1988) Arylpiperazine derivatives as high-affinity 5-HTIA serotonin ligands. J Med Chem 31:1968-1971.

Green DJ, Gillette R (1982) Circadian rhythm of firing rate recorded from single cells in the rat suprachiasmatic brain slice. Brain Res 245 : $198-200$.

Hery M, Faudon M, Dusticier G, Hery F (1982) Daily variations in serotonin metabolism in the suprachiasmatic nucleus of the rat: influence of oestradiol impregnation. J Endocrinol 94:157-166.
Honma KI, Watanabe K, Hiroshige T (1979) Effects of parachlorophenylalanine and 5,6-dihydroxytryptamine on the free-running rhythms of locomotor activity and plasma corticosterone in the rat exposed to continuous light. Brain Res 169:531-544.

Johnson RF, Moore RY, Morin LP (1988a) Loss of entrainment and anatomical plasticity after lesions of the hamster retinohypothalamic tract. Brain Res 460:297-313.

Johnson RF, Morin LP, Moore RY (1988b) Retinohypothalamic projections in the hamster and rat demonstrated using cholera toxin. Brain Res 462:301-312.

Kaufman CM, Shimomura K, Colwell CS, Menaker M (1992) GABAergic agents which prevent light-induced phase shifts of the circadian system do not inhibit the photic regulation of Fos-like immunoreactivity in the hamster suprachiasmatic nuclei. Soc Neurosci Abstr 18:880.

Kornhauser JM, Nelson DE, Mayo KE, Takahashi JS (1990) Photic and circadian regulation of $\mathrm{c}$-fos gene expression in the hamster suprachiasmatic nucleus. Neuron 5:127-134.

Levine JD, Rosenwasser AM, Yanovski JA, Adler NT (1986) Circadian activity rhythms in rats with midbrain lesions. Brain Res 445: 222-227.

Liou SY, Shibata S, Ueki S (1986) Effect of monoamines on field potentials in the suprachiasmatic nucleus of slices of hypothalamus of the rat evoked by stimulation of the optic nerve. Neuropharmacology 25:1009-1014.

Lovenberg TW, Baron BM, de Lecea L, Miller JD, Prosser RA, Rea MA, Foye PE, Racke M, Stone AL, Siegel BM, Danielson PE, Sutclifte JG, Erlander MG (1993) A novel adenylate cyclase-activating serotonin receptor $\left(5 \mathrm{HT}_{7}\right)$ implicated in the regulation of mammalian circadian rhythms. Neuron 11:449-458.

Medanic M, Gillette MU (1992) Serotonin regulates the phase of the rat suprachiasmatic circadian pacemaker in vitro during the subjective day. J Physiol (Lond) 450:629-642.

Meijer JH, Rietveld WJ (1989) Neurophysiology of the suprachiasmatic circadian pacemaker in rodents. Physiol Rev 69:671-707.

Middlemiss DN, Fozard JR (1983) 8-Hydroxy-2-(di- $n$-propylamino) tetralin discriminates between subtypes of the $5 \mathrm{HT}_{1}$ recognition site. Eur J Pharmacul 90:151-153.

Miller JD, Fuller CA (1990) The response of suprachiasmatic neurons of the rat hypothalamus to photic and serotonergic stimulation. Brain Res 515:155-162.

Moore RY, Lenn NL (1971) A retinohypothalamic projection in the rat. J Comp Neurol 146:1-14.

Moore RY, Halaris AE, Jones BE (1978) Serotonin neurons of the midbrain raphe: ascending projections. J Comp Neurol 180:417-438.

Morin I.P, Blanchard J (1991) Depletion of brain serotonin by 5-7DHT modifies hamster circadian rhythm response to light. Brain Res 566:173-185.

Morin LP, Blanchard J, Moore RY (1992) Intergeniculate leaflet and suprachiasmatic nucleus organization and connections in the golden hamster. Vis Neurosci 8:219-230.

Newman GC, Hospod FE (1986) Rhythm of suprachiasmatic nucleus 2-deoxyglucose uptake in vitro. Brain Res 381:345-350.

Pickard GE (1982) The afferent connections of the suprachiasmatic nucleus of the golden hamster with emphasis on the retinohypothalamic projection. J Comp Neurol 211:65-83.

Prosser RA, Miller JD, Heller HC (1990) A serotonin agonist phaseshifts the circadian clock in the suprachiasmatic nuclei in vitro. Brain Res 534:336-339.

Prosser RA, Heller HC, Miller JD (1992) Serotonergic phase shifts of the mammalian circadian clock: effects of tetrodotoxin and high $\mathrm{Mg}^{2+}$. Brain Res 573:336-340.

Prosser PA, Dean RR, Edgar DM, Heller HC, Miller JD (1993) Serotonin and the mammalian circadian system: I. In vitro phase shifts by serotonergic agonists and antagonists. J Biol Rhythms 8:1-16.

Ralph MR, Menaker M (1989) GABA regulation of circadian responses to light. I. Involvement of $\mathrm{GABA}_{\mathrm{A}}$-benzodiazepine and $\mathrm{GA}$ $\mathrm{BA}_{\mathrm{B}}$ receptors. J Neurosci 9:2858-2865.

Ramirez AD, Ramirez VD, Meyer DC (1987) The nature and magnitude of in vivo 5-hydroxyindoleacetic acid output from 5-hydroxytryptamine terminals is related to specific regions of the suprachiasmatic nucleus. Neuroendocrinology 46:430-438.

Rea MA (1989) Light increases Fos-related protein immunoreactivity in the rat suprachiasmatic nuclei. Brain Res Bull 23:577-581.

Rea MA (1992) Different populations of cells in the suprachiasmatic nuclei express c-fos in association with light-induced phase delays 
and advances of the free-running activity rhythm in hamsters. Brain Res 579:107-112.

Rea MA, Buckley B, Lutton LM (1993a) Local administration of EAA antagonists blocks light-induced phase shifts and c-fos expression in the hamster SCN. Am J Physiol 265:R1191-R1198.

Rea MA, Michel AM, Lutton LM (1993b) Is c-fos expression necessary and sufficient to mediate light-induced phase advances? J Biol Rhythms 8:S59-S64.

Roca AL, Weaver DR, Reppert SM (1993) Serotonin receptor gene expression in the rat suprachiasmatic nucleus. Brain Res 608:159165.

Rusak B, Zucker I (1979) Neural regulation of circadian rhythms. Physiol Rev 59:449-526.

Rusak B, Robertson HA, Wisden W, Hunt SP (1990) Light pulses that shift rhythms induced gene expression in the suprachiasmatic nucleus. Science 248:1237-1240.

Selim M, Glass JD, Hauser UE, Rea MA (1993) Serotonergic inhibition of light-induced Fos protcin expression and extracellular glutamate in the suprachiasmatic nuclei. Brain Res 621:181-188.

Shibata S, Oomura Y, Kita H, Hattori K (1984) Responses of suprachiasmatic nucleus neurons to optic nerve stimulation in rat hypothalamic slice preparation. Brain Res 302:83-90.
Shibata S, Liou SY, Ueki S (1986) Influence of excitatory amino acid receptor antagonists and of baclofen on synaptic transmission in the optic nerve to the suprachiasmatic nucleus of the rat hypothalamus. Neuropharmacology 25:403-409.

Shibata S, Tsuneyoshi A, Hamada T, Tominaga K, Watanabe S (1992) Phase resetting effect of 8-OH-DPAT, a serotonin 1 A receptor agonist, on the circadian rhythm of firing rate in the rat suprachiasmalic nuclei in vitro. Brain Res 582:353-356.

Smale L, Michels KM, Moore RY, Morin LP (1990) Destruction of the hamster serotonergic system by 5,7-DHT: effects on circadian rhythm phase, entrainment, and response to triazolam. Brain Res 515:9-19.

Szafarczyk A, Ixart G, Alonso G, Malaval F, Nouglier-Soule J, Assenmacher I (1981) Effects of raphe lesions on circadian ACTH, corticosterone and motor activity rhythms in free-running blinded rats. Neurosci Lett 23:92-97.

Tominaga K, Shibata S, Ueki S, Watanabe S (1992) Effects of 5-HT ${ }_{1 \mathrm{~A}}$ agonists on the circadian rhythm in wheel running activity in hamsters. Eur J Pharmacol 214:79-84. 